\title{
Memória e História dos EMEMCES: perspectivas da articulação da educação superior e educação básica com o respeito às diferenças
}

\author{
Memory and History of EMEMCES: perspectives of the \\ articulation of higher education and basic education with \\ respect for differences
}

\section{Memoria e Historia de EMEMCE: perspectivas de vincular la educación superior y la educación básica respetando las diferencias}

\author{
Diomar das Graças Motta ${ }^{1}$ \\ ORCID: http://orcid.org/0000-0002-5842-9366
}

\author{
Alda Margarete Silva Farias Santiago ${ }^{2}$ \\ ORCID http://orcid.org/0000-0002-6603-3716
}

\begin{abstract}
Resumo: As edições do Encontro Maranhense sobre Mulheres e Relações de Gênero no Cotidiano Escolar (EMEMCE) constituíram-se importante veículo difusor das experiências das mulheres em âmbito local, nacional e internacional. O registro desse evento mostra a participação das mulheres na construção da história da educação, em diferentes contextos e épocas. Os estudos de Perrot (2005), Ricoeur (2007) e Molina (2004), entre outros, auxiliam na compreensão acerca das percepções do feminino e da relação com o tempo, concebido como lugar e memória, na perspectiva da construção e reconstrução de trajetória de vida das mulheres (BOURDIEU, 1996). Esse movimento tem sido imprescindível para que as trajetórias das mulheres, especialmente das mulheres professoras, ganhem sentido e espaço na trama da história da educação, uma vez que esse lugar tem sido pouco preenchido por elas, apesar da sua participação majoritária nas instituições de ensino. Assim, esse evento vem cumprindo, paulatinamente, o objetivo de garantir visibilidade às mulheres, e com vistas à intensificação desse propósito, o Simpósio Maranhense de Pesquisadoras (es) sobre Mulher, Relações de Gênero e Educação (SIMPERGEN) agregou-se ao EMEMCE desde a primeira edição, no ano de 2003. Decorrida mais de uma década, o EMEMCE e o SIMPERGEN apresentam vitalidade pela capacidade de articulação e constante expansão.
\end{abstract}

Palavras-chave: EMEMCE. Relações de Gênero. Mulheres. UFMA.

\footnotetext{
1 Possui graduação em Pedagogia com Habilitação em Administração do ensino de primeiro e segundo graus, pela Universidade Federal do Maranhão (1971); Mestrado em Educação com a dissertação Assistência Técnica e Rendimento Escolar pelo Instituto de Estudos Avançados em Educação da Fundação Getúlio Vargas - RJ (1978); e Doutorado em Educação com a tese Mulheres Professoras na Política Educacional no Maranhão pela Universidade Federal Fluminense - RJ (2000). Atualmente é professora associada II, aposentada com atividade no PPGE- Programa de PósGraduação (Mestrado em Educação), na coordenação do GEMGe- Grupo de Estudos e Pesquisa sobre Mulheres e Relações de Gênero da Universidade Federal do Maranhão. Tem experiência na área de Educação, com ênfase em História da Educação e História das Mulheres Professoras, atuando principalmente nos seguintes temas: Maranhão, Educação, História, Mulher e Feminismo.

${ }_{2}^{2}$ Doutora em Educação Brasileira pela Universidade Federal do Ceará (2019), Mestra em Educação pela Universidade Federal do Maranhão (2015);Possui graduação em Pedagogia pela Universidade Federal do Maranhão (2003).
} 
Abstract: The editions of the Maranhense Meeting on Women and Gender Relations in School Life (EMEMCE) were an important vehicle for disseminating women's experiences at local, national and international levels. The record of this event shows the participation of women in the construction of the history of education, in different contexts and times. The studies by Perrot (2005), Ricoeur (2007) and Molina (2004), among others, help to understand the perceptions of the feminine and the relationship with time, conceived as place and memory, in the perspective of the construction and reconstruction of trajectory of life for women (BOURDIEU, 1996). This movement has been essential for the trajectories of women, especially women teachers, to gain meaning and space in the history of education, since this place has been little filled by them, despite their majority participation in educational institutions. Thus, this event has gradually fulfilled the objective of guaranteeing visibility for women, and with a view to intensifying this purpose, the Maranhense Symposium of Researchers (s) on Women, Gender Relations and Education (SIMPERGEN) has joined EMEMCE since the first edition, in 2003. After more than a decade, EMEMCE and SIMPERGEN are vital for their capacity for articulation and constant expansion.

Keywords: EMEMCE. Gender relations. Women. UFMA.

Resumen: Las ediciones de la Reunión de Maranhão sobre la Mujer y las Relaciones de Género en la Vida Escolar (EMEMCE) convertieronse en importante vehículo para la difusión de las experiencias de mujeres a nivel local, nacional e internacional. El registro de este evento demuestra la participación de las mujeres en la construcción de la historia de la educación, en diferentes contextos y épocas. Los estudios de Perrot (2005), Ricoeur (2007) y Molina (2004), entre otros, apoyan a comprender las percepciones de lo femenino y la relación con el tiempo, concebido como lugar y memoria, desde la perspectiva de la construcción y reconstrucción de la trayectoria vital de la mujer (BOURDIEU, 1996). Este movimiento fue imprescindible para que las trayectorias de las mujeres, especialmente las de las profesoras, ganen significado y espacio en el tejido de la historia de la educación, ya que este lugar ha sido poco ocupado por ellas, a pesar de su participación mayoritaria en las instituciones educativas. Por lo tanto, este evento ha cumplido poco a poco el objetivo de garantizar la visibilidad de las mujeres y, con miras a intensificar este propósito, el Simposio de Investigadoras(es) de Maranhão sobre la Mujer, las Relaciones de Género y la Educación (SIMPERGEN) se ha añadido al EMEMCE desde su primera edición en 2003. Después de más de una década, EMEMCE y SIMPERGEN presentan vitalidad por su capacidad de articulación y expansión constante.

Palabras claves: EMEMCE. Relaciones de Género. Mujeres. UFMA.

\section{INTRODUÇÃO}

O EMEMCE (Encontro Maranhense sobre Educação, Mulheres e Relações de Gênero no Cotidiano Escolar) foi concebido a partir da crença de que "a prática é fundamental para uma aprendizagem eficaz". Daí, no ano de 2003, o Grupo de Estudos, Pesquisa, Educação sobre Mulheres e Relações de Gênero (GEMGe), implantado em fevereiro de 2002, no Departamento de Educação II (DE II) da Universidade Federal do Maranhão (UFMA) instituiu um evento que se inserisse na tradição da divulgação do conhecimento produzido no seu seio.

Ao buscar essa inserção, tinha-se como perspectiva a interdisciplinaridade dos conhecimentos produzidos, com vistas à articulação da educação superior com a educação básica. 
A centralidade dessa articulação derivou do objetivo precípuo do GEMGe, que é a visibilidade da pessoa mulher, enquanto sujeito e objeto dos estudos e pesquisas no espaço educacional.

Com vistas a esse objetivo, agregou-se ao EMEMCE o Simpósio Maranhense de Pesquisadoras (es) sobre Mulher, Relações de Gênero e Educação (SIMPERGEN), evento este resultante da luta pela ampliação dos estudos e pesquisa sobre a temática, em especial no trato da mulher-professora, que tem pouca prevalência, tanto nos estudos feministas, como na pesquisa histórica.

Logo, o registro sobre o itinerário das edições do EMEMCE e do SIMPERGEN é também um instrumento fundamental para que a memória não seja secundarizada. A retomada do percurso alinha-se ao que disse Michelle Perrot (2005, p. 14) acerca da história das Mulheres: "É o olhar que faz a História". Nessa perspectiva, pontuamos o que foi e são o EMEMCE e o SIMPERGEN, que acontecem, paralelamente, na UFMA, ora promovidos pelo Programa de PósGraduação em Educação (PPGE), por meio do GEMGe, com apoio do Núcleo Interdisciplinar de Estudos e Pesquisas sobre Mulher, Cidadania e Relações de Gênero (NIEPEM), afiliado à Rede Feminista Norte e Nordeste de Estudos e Pesquisas sobre Mulher e Relações de Gênero (REDOR).

Assim, a cada edição, o EMEMCE e o SIMPERGEN oportunizam à comunidade acadêmica debates e proposições sobre temáticas que incidem diretamente sobre as mulheres no ambiente escolar, por meio de suas articulações com as diferentes dimensões da vida humana em sociedade, considerando as percepções sobre o feminino em diferentes épocas e espaços, tanto na educação superior como na educação básica.

A eleição das temáticas dos referidos eventos surge das sessões de estudos e dos objetos das pesquisas desenvolvidos pelos membros do GEMGe, em consonância com as transformações sociais e políticas operadas no Brasil e no mundo. Estas traduzidas no arcabouço normativo legal e materializado, sobretudo em ações afirmativas que colocaram em relevo a pessoa mulher, como bem atestam as diversas produções científicas dos últimos anos, que revelam o significativo crescimento de investigações sobre as mulheres, inclusive as mulheres professoras.

Logo, o tempo emerge como categoria organizadora da interpretação da memória e da história dos EMEMCEs e dos SIMPERGENs, já que "toda 
interpretação é uma atribuição de sentido ao vivido" (RICOUER, 2007, p. 84). Dessa maneira, o GEMGe é o lugar acadêmico e social composto de diversos tempos e artefatos que informam e permitem registrar as experiências desses eventos, no sentido do que ocorreu e de como ocorreu, buscando a inteligibilidade necessária à compreensão, por meio da argumentação, conforme os espaços e tempos dessas experiências, assim como os horizontes de expectativas de cada época em que se realizaram.

Destarte, apresentamos os eventos, com ênfase nas temáticas de sustentação e respectiva estrutura.

\section{TEMÁTICAS ELEITAS}

\section{1 Memória e Mulheres Professoras}

Na edição do I EMEMCE e o I SIMPERGEN realizada no período de 5 a 7 de agosto de 2003, o ponto de partida foi a memória de mulheres professoras, mediante a construção de trajetórias e reprodução de vivências no cotidiano escolar. O propósito foi dar visibilidade ao legado educacional maranhense, por meio da pessoa-mulher, sempre na articulação da educação básica e a educação superior, com vistas ao respeito às diversidades.

O mesmo foi ambientado na hoje Cidade Universitária D. José Delgado, no Campus do Bacanga, no Auditório Central, em São Luís. A conferência de abertura, intitulada "Relações de Gênero e Interdisciplinaridade", foi proferida pela Prof ${ }^{\mathfrak{a}}$ Dr $^{\mathrm{a}}$ Vera Maria de Almeida Corrêa, da Universidade Estadual do Rio de Janeiro (UERJ).

A estrutura desta edição foi constituída por dois Eixos Temáticos: I - A recuperação da categoria gênero no cotidiano escolar; e II- Memória educacional e relações de gênero. A partir destes, foram agrupadas as Comunicações com os seguintes temas: Corpo e Sexualidade; Infância e Gênero; Identidade de Gênero e Etnia; Gênero, Escola e Família; Prática Pedagógica e Relações de Gênero. Apesar da incansável divulgação do evento, só contamos com 20 trabalhos inscritos, dos quais 15 foram aceitos.

Tivemos três Mesas Redondas, a saber: Educação, Relações de Gênero e Linguagem; Educação e Masculinidade Docente; e Educação Pesquisa e Relações de Gênero. 
Foram proferidas duas outras palestras: "As Mulheres no Magistério" pela Prof ${ }^{a}$ Drª Marta Maria Leone Lima, da Universidade Federal da Bahia (UFBA); e "A Teoria Feminina e a Educação" pela Prof ${ }^{a}$ Dr $^{\mathrm{a}}$ Maria Eulina Pessoa de Carvalho, da Universidade Federal da Paraíba (UFPB). O evento foi encerrado pela Prof $^{\underline{a}} \operatorname{Dr}^{\mathrm{a}}$ Maria do Amparo Borges Ferro, da Universidade Federal do Piauí (UFPI) com a palestra "Memória e Relações de Gênero".

Esta edição do I EMEMCE e do I SIMPERGEN foi materializada com a obra: "Gênero em Debate: construindo e compreendendo a teoria feminista no cotidiano escolar", com organização da Prof ${ }^{a}$ Dr $^{a}$ Diomar das Graças Motta, publicado pela EDUFMA, 2008. A mesma contém 10 textos proferidos nas palestras e nas mesas redondas.

Desta feita, teoria e prática se imbricaram por pesquisas realizadas ou em andamento, não só no espaço maranhense como de outros estados do Nordeste e Sudeste brasileiros.

\subsection{Territorialidade e Cultura Escolar}

O II EMEMCE e o II SIMPERGEN, que aconteceram de 9 a 12 de setembro de 2009, trataram da Territorialidade e Cultura Escolar, sendo o território compreendido como um "espaço político, por excelência, campos de lutas e de poder, onde se realizam determinadas ações". (MOLINA, 2004, p.53). Nesta segunda edição, buscou-se promover um espaço de discussões sobre as questões de gênero, territorialidade e cultura nos espaços escolares, público e privado, campesino e urbano, religioso e laico, estimulando o desenvolvimento de pesquisas nessas áreas no chão maranhense.

Com este propósito, ao lado da diversidade de interesses das/os pesquisadoras/es da área, contamos com três eixos temáticos: I- Relações de Gênero, Territorialidade e Identidades; II- (Des) Territorialidade e as Instituições Religiosas; e III- Memória, Corpo e Literatura no Território Escolar, trabalhados em conferências, painéis e comunicações, sempre proporcionando o espaço para discussão de novos trabalhos e pesquisas concluídas e em andamento. Para os grupos de pesquisas das Universidades locais e de outros estados, foi uma oportunidade de aprofundamento e avaliação do crescimento da produção científica na temática eleita. 
Na sessão Conferências, a $\operatorname{Prof}^{\mathrm{a}}{ }^{\mathrm{Dr}}{ }^{\mathrm{a}}$ Temis Gomes Parente, da Universidade Federal do Tocantins (UFT), abriu o evento com o tema: "A Territorialidade e Cultura Escolar numa Perspectiva de Gênero: a revolução silenciosa de mulheres em suas práticas escolares". O Prof. Dr. Lyndon de Araújo Santos, da Universidade Federal do Maranhão (UFMA) abordou "A Laicidade e a Religiosidade nas Relações de Gênero no Território Escolar". Já a Prof ${ }^{\mathrm{a}}$. Dr ${ }^{\mathrm{a}}$. Maria Mary Ferreira, também da UFMA, discutiu "As Relações de Gênero no Espaço das Políticas Públicas de Educação".

Os Painéis Temáticos apresentaram leituras das maneiras como as relações de gênero interagem nos mais variados territórios. Assim, foram discutidos nos três painéis: a Educação e as Relações de Gênero na (des) Territorialidade Maranhense, Educação e Território Corporal Feminino e Masculino, Educação e as Relações de Gênero no Chão Escolar.

Nesta segunda edição, dos trabalhos inscritos, 27 (vinte e sete) foram apresentados, demonstrando, naquele momento, os avanços das pesquisas no campo das relações de gênero nas universidades brasileiras e, particularmente, nas maranhenses. A obra Gênero e Debate: Territorialidade e Cultura Escolar foi organizada pelas professoras Diomar das Graças Motta e Elisângela Santos de Amorim. Editada pela EDUFMA em 2009. Nela encontram-se ao lado das Conferências, oito textos, oriundos dos Painéis Temáticos.

\subsection{Masculinidades nas Relações de Gênero no Espaço Escolar}

Com a temática das Masculinidades nas relações de gênero no espaço escolar, o III EMEMCE e III SIMPERGEN foi realizado de 29 de novembro a 2 de dezembro de 2011, objetivando: a) aproximar a comunidade acadêmica dos estudos sobre a construção de masculinidades nas práticas discursivas e nas relações de gênero no cotidiano escolar; b) equilibrar o foco colocado nas identidades femininas com a crise da identidade masculina; c) promover a articulação entre os diversos grupos de pesquisa que integram os estudos feministas, de mulheres e de relações de gênero, numa perspectiva sobre as masculinidades; e d) incentivar o desenvolvimento de estudos e pesquisas na área, a partir das produções apresentadas no evento. 
A Conferência de Abertura, proferida pela $\operatorname{Prof}^{a} \operatorname{Dr}^{a}$. Maria Natália Pereira Ramos, da Universidade Aberta de Lisboa (UAL), teve como tema: A Escola nas construções das Masculinidades (hegemônicas e subalternas) no seu Cotidiano. Registra-se que esta terceira edição marca o início das participações de pesquisadores internacionais no EMEMCE e no SIMPERGEN e em face da ampliação da sua abrangência e articulação com instituições estrangeiras, uma integrante do GEMGe realizou estágio Pós-Doutoral junto ao Centro de Estudos das Migrações e das Relações Interculturais (CEMRI) da Universidade Aberta de Lisboa, estabelecendo, assim, uma articulação internacional dos estudos sobre educação, mulheres e relações de gênero no cotidiano escolar com a colaboração de Portugal.

A conferência de encerramento teve como tema: "A Paternidade "antecipada" na Percepção das Instituições: família e escola", proferida pelo Prof. Dr. Jorge Luís Cardoso Lyra da Fonsêca - Instituto Papai - PE.

Contamos com quatro Painéis Temáticos, a saber: 1- Masculinidades na Filosofia e nas Ciências; 2 - Uma Abordagem do Discurso: "des" construção das identidades sociais em sala de aula; 3- Masculinidades na produção de Intelectuais da Educação e 4- A Sexualidade no Campo Científico.

Os Eixos Temáticos foram assim definidos: 1- Relações de Gênero, Masculinidades Hegemônicas, Instituições Escolares; 2- Homofobia, Direitos Humanos, Religião, Cidadania; 3- Masculinidades nas obras Didáticas, Literárias e Científicas; 4-Masculinidade, Currículo e Prática Docente; e 5- Os Homens e as Masculinidades: sexualidade e reprodução.

Face a esta edição, foi publicada a obra: Gênero em Debate: masculinidades nas relações de gênero no espaço escolar. A mesma foi organizada pelas professoras Diomar das Graças Motta e Raimunda Nonata da Silva Machado e editada pela EDUFMA, em 2007. Contém sete textos apresentados durante o evento nas palestras e mesas redondas.

\subsection{Diversas Faces da Violência contra a Mulher no Cotidiano Escolar}

O IV EMEMCE e o IV SIMPERGEN foram realizados no período de 25 a 28 de novembro de 2013, tendo como tema central as Diversas faces da violência contra a mulher no cotidiano escolar: um lugar para as discussões, reflexões e produção coletiva sobre educação, mulheres e espaço escolar. 
A violência é um fenômeno que tem sido foco de crescentes discussões, debates e pesquisas que visam compreendê-la, a partir de diferentes contextos, sejam estes de âmbito local ou nacional ou internacional. Tal fenômeno, também, adentra os domínios do espaço escolar - uma vez que as escolas refletem as condições sociais nas quais estão inseridas - lugar no qual o cotidiano de professoras, professores, alunas e alunos é invadido por diferentes atitudes reconhecidas como violentas e, diante das quais, estes sujeitos ora podem ocupar a posição de vítimas, ora de testemunhas, ora de autores.

Como nos lembra a professora Marilena Chauí," a violência é violação da integridade física e psíquica, da dignidade humana de alguém" $(1995$, p.337) e envolve aspectos culturais, históricos e individuais que provocam danos profundos e, por vezes, irreparáveis. Daí que (re) conhecer as diversas faces deste fenômeno complexo, que é a violência, no cotidiano escolar é importante, muito embora este seja um objeto de estudo distante de um consenso entre todas as áreas de conhecimento que a investiga.

Com base nessas reflexões, esse evento proporcionou a aproximação entre a Academia e as diversas instâncias da sociedade, como o Ministério Público do Estado do Maranhão, por meio da Promotoria de Justiça de Defesa da Mulher e da Promotoria de Justiça de Defesa da Educação, assim como a Assembleia Legislativa do Estado do Maranhão, na pessoa da então Deputada Eliziane Gama, representantes de entidades civis, estudiosos do assunto, oriundos do Maranhão e de outros estados, além da participação de palestrante internacional, mais precisamente, da Espanha.

Assim, a Conferência de Abertura dessa edição foi proferida pelo Prof. Dr. Valentín Martínez-Otero Pérez, da Facultad de Educacíon da Universidad Computence - Madrid e teve como título: Violencia contra las mujeres em la escuela: reflexión sobre sus causas y soluciones. Ademais, o evento foi estruturado em torno de cinco eixos temáticos. Ao lado de duas conferências, dois painéis temáticos; e da promoção do espaço, intitulado de Diálogos das Interfaces. As atividades culturais perpassaram toda a programação, com destaque para o Cine Mulher, cuja linguagem audiovisual propiciou reflexões sobre a configuração da mulher em diferentes fases da vida e em diferentes espaços, entre eles, o espaço escolar. 
A Comissão organizadora do evento também abriu espaço para a exposição de fotografias que contemplaram as áreas de Educação, Mulheres, Relações de Gênero, Violências e temas afins. A sessão ocorreu na noite de 25 de novembro de 2013, sendo bastante prestigiada.

Em paralelo, houve lançamentos de livros e revistas de caráter científico e qualidade reconhecida nas áreas abrangidas pela temática do evento. $\mathrm{Na}$ oportunidade, foi lançada a Cartilha "Violência contra a Mulher: diálogo com a escola, o que os olhos não veem o corpo inteiro sente" de autoria da $\operatorname{Prof}^{a}$. $\operatorname{Dr}^{a}$. Walkíria de Jesus França Martins e da Prof ${ }^{a}$. Ma. Marianne Christina Campos Machado.

\subsection{Intergeracionalidade, Gênero e Educação}

No período de 14 a 17 de setembro de 2015 realizamos o $\mathrm{V}$ EMEMCE e $\mathrm{V}$ SIMPERGEN, promovendo espaços de discussão em torno da temática: Intergeracionalidade, Gênero e Educação. O principal objetivo foi analisar as relações intergeracionais e de gênero, por meio do embate de tradições, valores, costumes e saberes, visibilizando a troca construtiva de experiências nos espaços educacionais, reconhecendo seus sujeitos como produtores e transmissores de saberes. Este evento deu ênfase à troca de experiências entre professoras envelhescentes, idosas e seus alunos/as, valorizando e incentivando a disseminação de saberes e a manutenção de vínculos entre as gerações.

Desse modo, esta edição propôs espaços de reconhecimento de saberes intergeracionais como um movimento etário de contato e solidariedade social, já que, "a sociedade capitalista desarma o velho, mobilizando mecanismos pelos quais oprime a velhice, destrói os apoios da memória e substitui a lembrança pela história oficial celebrativa" (CHAUÍ, 1994, p. 18). Com isso, impõe barreiras a aprendizagens recíprocas, desvaloriza a memória individual e a função social da terceira idade que é: "lembrar e aconselhar [...] unir o começo e o fim, ligando o que foi e o porvir". (CHAUÍ, 1994, p. 18).

Com isso, a metodologia Diálogo das Interfaces se consagrou como "Espaço de saberes e vivências intergeracionais", mediante exposição dialógica por representantes de instituições que desenvolvem atividades intergeracionais, especialmente aquelas voltadas para o público idoso. As instituições participantes, 
desta atividade, foram: Serviço Social do Comércio do Maranhão (SESC) com Adalgisa Zaidan Drumond; Centro de Atenção Integral à Saúde do Idoso (CAISI) com Genaina Moreira Silva; Universidade Integrada da Terceira Idade (UNITI/UFMA) com Hortência Maciel Gago Araújo e Espaço da Gente (EG) com Maria Zali Borges Sousa San Luca.

No Cine Gerações tivemos a exibição e discussão do filme: A Balada de Narayama (1983) de Shohei Imamura (Japão), potencializado com a palestra sobre "Velhice e envelhecimento no cinema: perspectiva histórica, intercultural e de gênero", proferida pelo Prof. Dr. Lineu Norio Kohatsu, do Institituto de Psicologia da Universidade de São Paulo (USP).

A conferência de abertura foi proferida pelo Prof. Dr. Francis Musa Boakari, da Universidade Federal do Piauí (UFPI) e a de encerramento pela Prof $^{a}{ }^{a} r^{a}$ Maria Natália Pereira Ramos, da Universidade Aberta de Lisboa (UAL).

Nessa edição, tivemos dois Painéis Temáticos: 1) Intergeracionalidade nos espaços sociais, que teve como debatedoras: $\operatorname{Prof}^{\mathrm{a}} \mathrm{Dr}^{\mathrm{a}}$ Jacira do Nascimento Serra

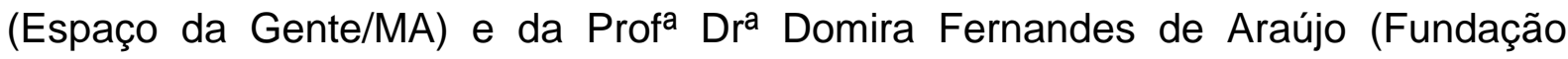
Visconde de Cairu/BA); e, 2) Intergeracionalidade nas docências, com as debatedoras: $\operatorname{Prof}^{\mathrm{a}} \mathrm{Dr}^{\mathrm{a}}$ Iran de Maria Leitão Nunes (UFMA) e a $\operatorname{Prof}^{\mathrm{a}} \mathrm{Dr}^{\mathrm{a}}$ Kilza Fernanda Moreira de Viveiros (UFMA/UFRN).

De forma inovadora, foram realizadas Rodas de Conversa, visando propiciar a interlocução entre crianças, jovens e adultos, a partir dos relatos de experiências de mulheres idosas. As conversas e trocas de experiências intergeracionais foram direcionadas pelas seguintes temáticas: 1 ) Mulher nas Ciências: a fitoterapia, com a Profa. Dr ${ }^{a}$. Terezinha Soares Fernandes do Rêgo; 2) Mulheres na sala de aula: com a Professora e Gastrônoma, $\mathrm{Sr}^{\mathrm{a}}$. Admée Belo Rodrigues Duailibe; 3) Mulheres na Literatura: com a Poetisa e Compositora Sr ${ }^{\mathrm{a}}$. Raimunda Pinheiro de Souza Frazão; e, 4) Mulheres afrodescendentes e suas manifestações: Caixeiras do Divino e Mães de Santo, com a Sr ${ }^{\text {a }}$. Luzia Assunção Costa.

Para Muxel (1996), através da circulação da palavra é que as mulheres contribuem mais para manter vivos os elos entre as gerações. Isso faz delas depositárias privilegiadas do conhecimento genealógico e da memória da linhagem, cuja transmissão é um elemento essencial na formação da identidade individual. 
Portanto, relembrar, reviver e recontar as reminiscências das mulheres nas relações intergeracionais é contar com a participação de crianças, jovens e idosos, é incentivar e aproveitar essas trocas, sem idealizar ou negligenciar comportamentos presentes em nosso cotidiano, principalmente social. Nesta perspectiva, torna-se evidente o significativo contributo da educação em seus diversos espaços, conforme referenda Puerta.

É papel de La Educación sería, em tal sentido, promover situaciones, tareas y demandas próprias de los processos de enseñanza y aprendizaje que, lógicamente, conllevan otros aspectos de los que promueven El envejecimento activo, El óptimo o El productivo. (PUERTA, 2012, p. 118).

O V EMEMCE, neste caso específico, considerou fundamental preparar para a velhice os jovens da atualidade. Daí a importância de se promover um encontro entre gerações, priorizando as relações de gênero, por meio do embate de tradições, valores, costumes e saberes, visibilizando à troca construtiva de experiências nos espaços educacionais, reconhecendo seus sujeitos como produtores e transmissores de saberes.

Com a devida atenção ao fortalecimento da articulação educação superior e educação básica, a expansão territorial do GEMGe se impôs e realizou a primeira edição do evento, no continente maranhense. A discussão da temática recaiu na do V EMEMCE E V SIMPERGEN - Intergeracionalidade, Gênero e Educação. Foi localizado geograficamente no Centro-Sul maranhense, no município de Grajaú, há 564,9 km da capital São Luís. Foi sediado no Campus da UFMA de Grajaú, no período de 31 de março a 2 de abril de 2016, mediante a co-participação da direção deste Campus e do Grupo de Estudos e Pesquisa sobre Educação, História e Mulheres (GEPEHM), coordenado pela Profa ${ }^{-}$Mestra Patrícia Costa Ataíde, uma integrante do GEMGe.

A Conferência de abertura foi proferida pela Prof ${ }^{a}$. Dr $^{\mathrm{a}}$. Iran de Maria Leitão Nunes (PPGE/UFMA) e a de encerramento pela Prof ${ }^{\mathrm{a}}$. Dr ${ }^{\mathrm{a}}$. Diomar das Graças Motta. Foram apresentadas treze Comunicações orais, distribuídas entre os eixos definidos no V EMEMCE e V SIMPERGEN, da capital São Luís.

Realizou-se o painel temático sobre "Educação e Mulheres numa Perspectiva Intergeracional", tendo como debatedoras integrantes do GEMGe: Prof ${ }^{a}$. Dr ${ }^{a}$.. Raimunda Nonata da Silva Machado (Docente UFMA/São Luís), Prof ${ }^{a}$. Ma. Maria do Socorro Coelho Botelho (Docente IFMA/São Luís) e Prof ${ }^{a}$. Ma. Maria José Lobato Rodrigues (Docente SEDUC/SEMED/São Luís). 
Nesta edição foram desenvolvidas três oficinas: 1) "Quebrando Tabus" por Bianca Bueno do Nascimento (Mestranda PPGE/UFMA) e Prof ${ }^{a}$. Dr ${ }^{\mathrm{a}}$. Raimunda Nonata da Silva Machado (UFMA); 2) Experiências de mulheres professoras afrodescendentes na educação maranhense, por Heline Maria Furtado Silva (Mestranda PPGEEB/UFMA); e, 3) Mulheres Afrodescendentes na Literatura: aspectos intergeracionais na obra de Maria Firmina dos Reis, pelas docentes: Prof ${ }^{\mathrm{a}}$. Ma. Alda Margarete Silva Farias Santiago (GEMGe/UFMA) e Prof ${ }^{a}$. Ma. Lissandra Mendes Fraga (SEMED/São Luís).

O Diálogo das Interfaces também se constituiu como "Espaço de saberes e vivências intergeracionais", tendo a participação de representantes das seguintes instituições: 1) Centro de Referência de Assistência Social (CRAS/Grajaú): com Evanir Gama Pereira; 2) Fundação Nacional do Índio (FUNAI/Grajaú): com Raimon Reimere dos Santos Mota; 3) Sociedade São Vicente de Paulo/Casa do Idoso Raimundo Nava: com Raimundo Nonato Santos Filho e 4) Secretaria de Educação do Maranhão (SEDUC/Grajaú): com Rodrigo Guará Nunes.

As Rodas de Conversa produziram trocas de experiências e saberes intergeracionais e foram enriquecidas pelas contribuições de: 1) Mulheres na saúde: a parteira Maria Aleluia da Conceição Pereira de Sousa; 2) Mulheres na sala de aula: professora e poetisa Maria do Socorro da Silva Oliveira; 3) Mulheres indígenas: Inês da Conceição Sousa; 4) Mulheres quilombolas: Ana Luíza Ribeiro.

As atividades do I EMEMCE e I SIMPERGEN no Continente, apesar de seguirem a metodologia da quinta edição, inovaram propondo maior aproximação com a comunidade acadêmica local, reunindo pesquisadoras (es) de outras cidades do estado do Maranhão.

\subsection{A Mulher Afrodescendente no Cotidiano Escolar}

O VI EMEMCE e o VI SIMPERGEN realizaram-se no período de 11 a 14 de setembro de 2017 no Centro Pedagógico Paulo Freire, na Cidade Universitária D. José Delgado em São Luís e teve como tema: A Mulher Afrodescendente no Cotidiano Escolar. O objetivo era amplificar os debates sobre as políticas públicas e a legislação educacional no interior das escolas, notadamente, as políticas voltadas para a formação docente e suas repercussões, no tocante à descendência de seus sujeitos, assim como a obrigatoriedade dos estudos sobre a história dos 
Memória e História dos EMEMCES: perspectivas...

afrodescendentes, por meio da Lei no 10.639/2003. Tinha como horizonte a Assembleia Geral da Organização das Nações Unidas (ONU), por meio de sua Resolução no 68/237, de 23 de dezembro de 2013, que instituiu a Década Internacional Afrodescendente, no período compreendido entre 1/1/2015 a $31 / 12 / 2024$, a fim de fomentar o respeito, a proteção e a garantia de direitos e liberdades fundamentais dos afrodescendentes.

Os Painéis Temáticos foram intitulados: Painel 1 - A produção e saberes de mulheres afrodescendentes; Painel 2 - A Afrodescendência na formação docente.

Por ocasião do V EMEMCE, foram criadas Rodas de Conversa e nestas a atividade foi intitulada Rodas de Vivência, abrindo-se espaço para que mulheres professoras afrodescendentes, que atuam no magistério superior, apresentassem relatos de experiências sobre suas práticas educativas com destaque para as questões étnico-raciais e as relações de gênero na educação superior.

As Comunicações Orais foram estruturadas em cinco Eixos Temáticos decorrentes de estudos, pesquisas e experiências relacionadas ao objeto central do Evento, conforme registramos, a seguir: I: Afrodescendência feminina, relações de gênero e práticas de empoderamento no cotidiano escolar; II: Mulheres professoras afrodescendentes, discriminação, sexualidade e religiosidade no contexto escolar; III: Pedagogias Afrocentradas e feminismo negro no debate acadêmico; IV: Mulheres afrodescendentes nas mídias, nas ferramentas digitais e nas obras didáticas e paradidáticas; V: As Mulheres afrodescendentes nos serviços gerais das instituições de ensino.

No período de 17 a 19 de outubro de 2018, o EMEMCE e o SIMPERGEN voltam a percorrer o território maranhense, tendo como destino o Campus VII da UFMA no município de Codó, para ampliar os debates sobre A Mulher Afrodescendente no Cotidiano Escolar, em sinal de reconhecimento e apreço aos saberes regionais, destacando a história, os costumes e valores da região, sempre em consonância com a metodologia do evento realizado em São Luís.

A conferência de abertura dessa edição teve como tema: "Diálogos de Mulheres Afrodescendentes no Cotidiano Escolar" e foi proferida pela Prof ${ }^{\underline{a}}$ Dr $^{\underline{a}}$ Gleys lally Ramos dos Santos, docente do curso de Relações Internacionais, da Universidade Federal do Tocantins (UFT). 
Os cinco Eixos Temáticos foram os mesmos do evento realizado em 2017, na cidade de São Luís. Os espaços para apresentação foram identificados com o nome: I - Sala Marielle Franco: Afrodescendência feminina, relações de gênero e práticas de empoderamento no cotidiano escolar; II - Sala Conceição Evaristo: Mulheres Professoras Afrodescendentes, Discriminação, Sexualidade e Religiosidade no contexto escolar; III - Sala Carolina de Jesus: Pedagogias Afrocentradas e feminismo negro no debate acadêmico; IV - Sala Maria da Penha: Mulheres afrodescendentes nas mídias, nas ferramentas digitais e nas obras didáticas e paradidáticas; e V-Sala Diomar Motta: As Mulheres afrodescendentes nos serviços gerais das instituições de ensino superior .

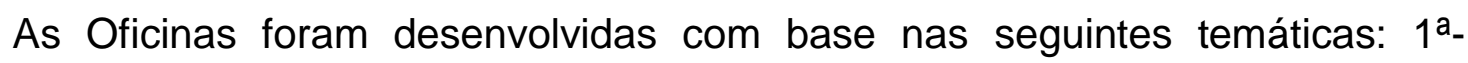
Libras (Prof ${ }^{\mathrm{a}}$ Ma. Amanda Sousa - IFMA/Codó); 2 ${ }^{\mathrm{a}}$ - Quebradeiras de Coco e Movimento Interestadual de Quebradeiras de Coco Babaçu - MIQCB (Prof ${ }^{\underline{a}}$ Natália Mouzinho - UFMA/Codó); 3 $3^{\text {a- }}$ Formatação de Trabalhos Acadêmicos (Prof ${ }^{a}$ Raimunda Nonata dos Santos Ferreira - UFMA/Codó); 4á- Cantando a Arte de Expressar (Prof. Thelvany Frazão Araújo (Academia Corpo e Forma/ Codó); 5âGênero e Diversidade na Escola (Prof ${ }^{\mathrm{a}}$ Dr $^{\mathrm{a}}$. Sirlene Mota Pinheiro da Silva UFMA/São Luís); 6 6- Educação Etnomatemática (Prof ${ }^{a}$ Ma. Maria do Carmo Alves da Cruz - UFMA/São Luís); 7ª- Microhistória e História Oral: Métodos e Técnicas aplicadas à temática de Gênero e Raça (Prof ${ }^{a}$ Ma. Jéssica Cristina Aguiar Ribeiro -

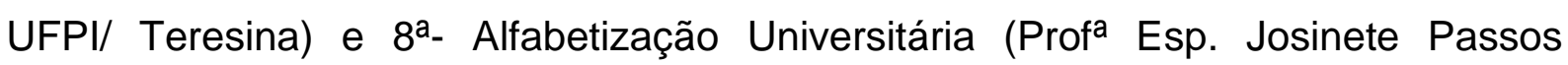
(UFMA/Codó)

As três Rodas de Conversa tiveram os seguintes temas: 1a: Professoras Afrodescendentes Universitárias; 2a: A Mulher Afrodescendente no Maranhão e a Mulher da África do Sul: diálogos intercontinentais; $3^{\mathrm{a}}$ : Mulheres Afrodescendentes no Cotidiano escolar: pesquisas e práticas.

\subsection{Feminismos nos Espaços Educativos}

No período de 10 a 13 de setembro de 2019, o Centro Pedagógico Paulo Freire foi novamente sede do VII EMEMCE e do VII SIMPERGEN, com a abordagem: "Feminismos nos espaços educativos". O referido tema atravessou todas as Conferências, Comunicações, Mesas e Diálogos, aglutinando um significativo número de pesquisadoras e pesquisadores, mostrando o vigor e a 
consolidação de ambos os eventos, ao longo de seus dezessete anos, buscando sempre garantir a visibilidade das mulheres.

A motivação teve como mola propulsora os cinquenta anos do movimento feminista da América Latina. A inspiração na obra organizada por Blay e Avelar (2018), centrada na América Latina não colonial, intitulada "50 anos de feminismos: Argentina, Brasil e Chile: A construção das mulheres como atores políticos e democráticos", afirmou o significado do tema e seu urgente questionamento.

Decorrido meio século, as conquistas obtidas no campo econômico e social, ainda que sentidas por poucas, a obra chama atenção pelo pequeno vínculo com a política, que destaca a exígua participação da mulher. Nesta, os valores igualitários, investigados e cerne dos feminismos, a mulher é quase ausente. Ausência que se estende em muitos espaços educativos, ainda que na dicionarização do Feminismo na língua portuguesa, seja a teoria que sustenta a igualdade política, social e econômica de ambos os sexos.

Mas esse significado não tem merecido o devido acatamento, como movimento que busca equilibrar a mulher ao homem no que atina aos direitos, emancipando-a jurídica, econômica e sexualmente.

Estas visões não são do conhecimento, quiçá do domínio de mulheres escolarizadas ou não. Logo, o GEMGe demonstra, mais uma vez, sua preocupação com a visibilidade da mulher e das construções teóricas, que a ajudam no seu existir em sociedades e épocas, que insistem em ignorá-la como pessoa. Tratar do FEMINISMO é contribuir para a importância de seu conhecimento, discussão e apreensão.

Desse modo, esta edição teve como objetivos: a) aprofundar a compreensão acerca da presença do feminismo e seu sentido nas sociedades do passado e do presente; b) enfrentar o feminismo como potência transformadora, contribuindo para retirá-lo das searas das polêmicas infindáveis; c) pensar nas questões teóricas do feminismo como enfrentamento das lutas pelos direitos humanos e pela justiça social; d) ressignificar o conceito de feminismo, sustentado na vivência da mulher professora e na perspectiva interseccional (como etnia e classe social, dentre outros) apoiada em uma análise teórico feminista, nos múltiplos campos do conhecimento. 
Daí por que a escolha dos Eixos Temáticos a seguir: I - Feminismo, política e poder; II- Feminismo, língua e linguagem; III- Feminismo, filosofia, ciências e tecnologias; IV - Feminismo práticas educativas, escolares e pedagógicas; e VFeminismo, arte e cultura.

Este evento contou com três Mesas-Redondas. Aa primeira intitulada: Feminismo, Religião e Espiritualidade, coordenada pela Prof. ${ }^{a}$ Doutoranda Maria José Lobato Rodrigues, e teve como expositores: Prof ${ }^{\mathrm{a}} \mathrm{Dr}^{\mathrm{a}}$ Iran de Maria Leitão Nunes, Prof $^{a}{ }^{-} r^{a}$ Maria de Lourdes Siqueira e o Prof. Dr. Lyndon de Araújo Santos.

A segunda Mesa-Redonda, com o tema: A Educação Básica e os Feminismos, foi coordenada pelo Prof. Dr. José Carlos de Melo e teve como participantes: Prof ${ }^{a}$ Dr $^{\mathrm{a}}$ Francisca das Chagas Lima, Prof ${ }^{\mathrm{a}} \mathrm{Dr}^{\mathrm{a}}$ Kilza Fernanda Moreira de Viveiros e da Profä. Doutoranda Maria da Penha Teófilo.

A terceira Mesa-Redonda abordou a Linguagem e os Feminismos e foi coordenada pela Prof $^{a}$ Dr ${ }^{\text {a }}$ Joelma Reis Corrêa e contou com a explanação das convidadas: Prof ${ }^{\mathrm{a}} \mathrm{Ma}$. Maria da Graça Reis Cardoso, Prof ${ }^{\mathrm{a}} \mathrm{Dr}^{\mathrm{a}}$ Sônia Maria Pereira Correia Mugschl e Prof ${ }^{a}{ }^{-a}{ }^{a}$ Veraluce da Silva Lima.

Os Diálogos das Interfaces foram estruturados em duas versões, o primeiro denominado: O Feminismo nos Grupos de Pesquisa, coordenado pela Prof ${ }^{a}$ Dr $^{a}$ Raimunda Nonata da Machado, e com a participação das pesquisadoras: Prof. ${ }^{a} \mathrm{Dr}^{\underline{a}}$ Tatiane da Silva Sales, Prof ${ }^{a} \mathrm{Dr}^{\mathrm{a}}$ Sandra Maria Nascimento Sousa, $\operatorname{Prof}^{\mathrm{a}} \mathrm{Dr}^{\mathrm{a}}$ Lourdes de Maria Leitão Nunes Rocha e Prof ${ }^{\mathrm{a}} \mathrm{Dr}^{\mathrm{a}}$ Dayna dos Santos Delmiro Costa.

O segundo Diálogo das Interfaces focalizou o Feminismo nos Movimentos Sociais e esteve sob a coordenação da Prof ${ }^{-}$Dra ${ }^{-a}$ Marilda da Conceição Martins e teve como apresentadoras: a Prof $^{\mathrm{a}} \operatorname{Dr}^{\mathrm{a}}$ Herli de Sousa Carvalho, Prof ${ }^{a}$ Elisângela Santos Amorim e a Prof ${ }^{\underline{a}} \mathrm{Dr}^{\mathrm{a}}$ Joelma Fernandes de Oliveira.

A conferência de abertura foi proferida pela $\operatorname{Prof}^{\mathrm{a}}{ }^{\mathrm{D}} \mathrm{r}^{\mathrm{a}}$ Vanessa Ribeiro Simon Cavalcanti, integrante do corpo docente da Universidade de São Paulo (USP) e a de encerramento, pela Prof ${ }^{\mathrm{a}}$ Dr ${ }^{\mathrm{a}}$ Maria Mary Ferreira, integrante do corpo docente da Universidade Federal do Maranhão (UFMA).

A exemplo das demais edições, este evento contou com significativa participação da comunidade acadêmica, assim como uma vasta programação cultural composta por apresentações musicais, lançamentos de publicações e condecorações. 


\section{A CONDECORAÇÃO}

\subsection{Razões}

A inserção do ato de condecorar objetivou complementar o evento, em seu aspecto político e social, em consonância com o pedagógico.

Esta constituiu a materialização dos saberes partilhados, sem, contudo, omitir o protagonismo da mulher-professora. Há gratidão por sua atuação, mas sem nenhuma expressão que a dignifique.

Nessa perspectiva, o GEMGe, mais uma vez, articulou teoria e prática, instituindo a Medalha Laura Rosa. Dentre os seus objetivos, procurou-se homenagear as que se destacaram no espaço educacional, conforme a temática eleita por cada edição.

A razão da escolha da medalha de forma circular é para expressar a intenção de celebrar, como algo memorável ou de pós-reconhecimento, portanto sem aresta.

É oportuno registrar que o vocábulo medalha tem origem controversa, segundo diferentes estudiosos. Seu surgimento na Idade Média é de acepção do grego metallon e no latim pós-clássico a grafia é medalha, usada até nossos dias.

A escolha da denominação Laura Rosa (1884-1976) foi uma homenagem àquela, que ao lado da professora normalista afrodescendente, tornou-se a primeira mulher sócia-coletiva da Academia Maranhense de Letras (AML), em 1943, rompendo uma tradição de trinta e cinco anos, ocupou a Cadeira de oㅡ 26, cujo patrono era o escritor e professor Antônio Francisco Leal Lobo (1870-1916), hoje ocupada por Carlos Thadeu Pinheiro Gaspar, atual presidente da AML.

Laura Rosa foi uma intelectual ativa, com envolvimento na literatura, na prosa, poesia, crônicas em jornais e revistas de âmbito local e nacional.

No campo educacional, foi responsável pela implantação do ideário do movimento pedagógico Escola Nova, que teve a contribuição do estadunidense John Dewey (1858-1952). No magistério inicia suas atividades no município de Caxias. Transferida para a cidade de São Luís, lecionou no Jardim de Infância Decroly e na Escola Normal. Como inspetora de ensino, implantou a Seção Técnica da Diretoria Geral da Instrução Pública, sendo uma de suas diretoras.

Essas razões, ao lado das temáticas de cada evento, recaíram sobre mulheres-professoras, num total de cinco em cada evento. 


\subsection{Pessoas condecoradas}

A instituição e distribuição da Medalha Laura Rosa, só ocorreu, a partir do II EMEMCE e II SIMPERGEN, em 2008, com a temática Territorialidades e Cultura Escolar. As condecoradas foram professoras que atuaram, também, em outros territórios, fora do ambiente escolar nas seguintes instituições.

1) Academia Maranhense de Letras -Ceres Costa Fernandes;

2) Câmara Municipal de São Luís - Lia Rocha Varella, falecida em 2010;

3) Centro Rural Universitário de Treinamento e Ação Comunitária em Codó/MA - Iramari de Jesus Queiroz;

4) Instituto Histórico e Geográfico do Maranhão (IHGM) - Eneida Vieira de Canedo Ostria, (falecida em 2017) e Joseth Coutinho Martins de Freitas.

Nos III EMEMCE e III SIMPERGEN realizados em 2011, com a temática Masculinidades nas Relações de Gênero no Espaço Escolar, não houve condecoração, devido às restrições econômicas.

Já nos IV EMEMCE e IV SIMPERGEN, em 2013 com a temática as Diversas Faces da Violência contra a Mulher no Cotidiano Escolar, achou-se por bem escolher as primeiras participantes do GEMGe implantado em fevereiro de 2002 sem contudo, haver articulação com a abordagem em questão. Foram as alunas:

- Diana Brito Diniz;

- Katia Regina Pinto;

- Maria Angélica dos Reis Cordeiro;

- Thatiane Maria Portela;

- Professora Kilza Fernanda Moreira de Viveiros.

Em 2015 no V EMEMCE e V SIMPERGEN, com a discussão sobre Intergeracionalidade, Gênero e Educação, as professoras agraciadas à época estavam na faixa etária de 62 anos a 102 anos e atuaram na Educação Básica e na Educação Superior. Foram elas:

- Conceição de Maria Ribeiro Quadros, falecida em 2016;

- Eulina Gomes Duarte Ferreira, falecida em 2018;

- Eunice Cutrim Lauande, falecida em 2019;

- Francisca da Silva Gomes;

- Silvandira Soares Almeida 
A mesma temática foi apresentada no I EMEMCE e I SIMPERGEN no continente, realizados em 2016 no município de Grajaú, com um acréscimo na inscrição da insígnia Mulheres Professoras Griôs, devido à circulação dos eventos. Contamos com professoras alfabetizadoras e do então ensino primário, indígenas e afrodescendentes.

- Ana de Souza Carvalho;

- Carmelita Lopes Guajajara;

- Maria Eugênia Guajajara;

- Maria do Socorro da Silva Oliveira;

- Rita de Cássia Lima Sarmento.

Com a temática "A mulher Afrodescendente no Cotidiano Escolar, O VI EMEMCE e o VI SIMPERGEN, realizados em 2017, outorgou a medalha às mulheres professoras de descendência africana e com exercício tanto na educação básica quanto na superior, com atuação nas áreas de ensino, pesquisa e gestão em instituições do sistema educacional e no sistema público, ao lado de inúmeras obras publicadas.

- Andréa Lúcia Rodrigues;

- Claudett de Jesus Ribeiro;

- Maria de Lourdes Siqueira;

- Maria Lúcia Ferreira;

- Maria Raymunda Araújo.

No ano seguinte, foi realizada a segunda edição no continente, na região dos cocais no município de Codó, com a mesma temática (A Mulher Afrodescendente no Cotidiano Escolar) recaindo a condecoração nas professoras:

- Maria Judith Dias Salazar;

- Maria Raimunda Mota Munis;

- Francisca Basílio da Silva;

- Maria do Carmo Araújo dos Santos;

- Maria das Graças Souza Rocha.

Com a regularidade bianual, em 2019 tivemos a sétima edição, na capital, São Luís que contemplou a temática: "Feminismos nos espaços educativos sendo agraciadas as estudiosas e pesquisadoras da teoria feminina na Universidade 
Federal do Maranhão (UFMA) e a primeira mulher professora a assumir o cargo máximo, na instância superior da instituição, foram as professoras doutoras:

- Elizabeth Sousa Abrantes;

- Lourdes de Maria Leitão Nunes Rocha;

- Maria Mary Ferreira;

- Nair Portela Silva Coutinho (Reitora);

- Sandra Marias Nascimento Sousa.

As condecorações têm contribuído para a valorização da atividade docente, bem como proporcionado incentivo e alegria para muitas, por ter sido a primeira, e talvez a única, menção de reconhecimento, em toda a sua trajetória profissional.

\section{ALGUMAS CONSIDERAÇÕES}

O surgimento e a consolidação das atividades científicas e culturais proporcionadas pelo EMEMCE e pelo SIMPERGEM, tendo o Grupo de Estudos e Pesquisa sobre Educação, Mulheres e Relações de Gênero (GEMGe), vinculado ao Programa de Pós-Graduação em educação (PPGE) da Universidade Federal do Maranhão, como entidade promotora das edições desses eventos, representam um marco para os estudos feministas no contexto da história da educação maranhense, tendo em vista a sua contribuição para a justa colocação/reposição das memórias e das histórias das mulheres no magistério local e regional.

Ademais, é preciso destacar as complexas operações para a realização de eventos científicos, especialmente nos últimos anos, em razão das constantes mudanças no cenário político e econômico do país, com fortes repercussões no seio das instituições de ensino, principalmente sobre as universidades.

Daí, destaca-se o apoio de instituições e pessoas que ao longo dos anos, contribuem ativamente para a realização das atividades científicas e culturais, que a cada edição, apresenta crescente número de participantes de diferentes localidades.

Desse modo, é legítimo registar o empenho do GEMGe no sentido de empreender esforços para manter a regularidade do EMEMCE e do SIMPERGEN, visto que ambos já integrados ao calendário de eventos científicos no Brasil, como bem atestam a identificação da procedência das pessoas inscritas, que revelam uma variedade de lugares e instituições que a cada dois anos submetem suas produções 
ao comitê científico, a fim de que possam apresentá-las à comunidade de pesquisadoras e pesquisadores.

Portanto, o EMEMCE e o SIMPERGEN têm se configurado como eventos em crescente número de participantes, programação renovada a cada versão, adequando-se à temática em foco. A exemplo das rodas de conversa como estratégia de saberes entre gerações; ampliação de sua abrangência de local para internacional, expansão intermunicipal, incluindo outros espaços para sediar o evento; além da divulgação da produção deles decorrentes (anais, livros e cartilha) em diversos espaços da Universidade Federal do Maranhão, numa perspectiva da articulação da educação superior e educação básica, com o respeito às diferenças. Fato revelado pelas temáticas escolhidas. 


\section{REFERÊNCIAS}

BOURDIEU, Pierre. As regras da arte: gênese e estrutura do campo literário. São Paulo: Companhia das Letras, 1996.

BLAY, Eva Alterman. AVELAR, Lúcia. 50 Anos de Feminismo: Argentina, Brasil e Chile: a construção das mulheres como atores políticos e democráticos. São Paulo: EDUSP, Fapesp, 2017.

CHAUì, Marilena. Convite à Filosofia. São Paulo: Editora Ática, 1994.

1995. . Marilena. Cultura política e política cultural. São Paulo: Editora Ática,

MARTINS, Walkiria de J. França. MACHADO, Marianne C. Campos. Violências Contra as Mulheres: diálogos com a escola, o que os olhos veem o corpo inteiro sente. São Luís, 2013.

MOLINA, Sérgio. Turismo y Ecologia. México: Trilhas, 2004.

MOTTA, Diomar das Graças (org.). Gênero em Debate: construindo e compreendendo a teoria feminista no cotidiano escolar. São Luís: Edufma, 2008.

MOTTA, Diomar das Graças. AMORIM, Elisângela Santos (Orgs). Gênero em Debate: Territorialidade e Cultura Escolar. São Luís: Edufma, 2009.

MOTTA, Diomar das Graças. MACHADO, Raimunda Nonata da Silva (Orgs) Gênero em debate: masculinidades nas relações de gênero no espaço escolar. São Luís: Edufma,2017.

MUXEL, Anne. Individu et mémoire familiale. Paris: Editions Nathan, 1996.

PERROT, Michelle. Minha história das mulheres. São Paulo: Contexto, 2005.

PUERTA, A.A.; AMARAL, R.M. Comparação da Educação Presencial com a Educação a Distância através de uma Pesquisa Aplicada. São Paulo: Contexto, 2012.

RICOUER, Paul. A memória, a história e o esquecimento. Campinas, SP: Editora da Unicamp, 2007. 